\title{
Remote-controlled robotic complex for underground mining
}

\author{
Vitalii Tauger, Niyaz Valiev, Evgenii Volkov, Denis Simisinov and Vitalii Adas \\ Ural State Mining University, 620144, Ekaterinburg, Russia
}

\begin{abstract}
As the global rich mineral deposits are becoming depleted, the deposit development is performed with a deeper bedding and in much more difficult mining and geological conditions. This circumstance determines both the increase in the labor intensity and development costs, and the increased likelihood of emergencies. In recent years, the accidents have become more frequent at the Russian mining enterprises, aggravated not only by the significant damages, but also by the casualties. The ongoing efforts to correct the tight situation do not have a perceptible effect. A complete exclusion of the presence of people underground should be considered as a drastic remedy for preventing human casualties. It can be achieved only through the use of machinery and technology for manless mining using the automated control systems. The Department of Engineering Mechanics of the Ural State Mining University has formed the concept of a "remote-controlled robotic complex for underground mining", according to which a surface-controlled system of mining equipment will absolve the miners from working underground. At present, the favorable conditions have been laid for combining the in-mine equipment and permanent installations into a single complex under the control of operators located on the soil surface. In accordance with the concept, the technological robotic complex is transformed into a mechatronic system of the underground mining equipment. The mechatronic system is divided into the separate subsystems by the types of equipment. Particular attention is paid to the automated complex remote-control system based on the telemetry principles using the latest means of data acquisition, conversion and transmission. The system interface provides the most efficient and error-free performance of the operator throughout the entire shift. The concept implementation of the remote-controlled robotic complex in the mining industry will allow not only to avoid the tragic consequences of emergencies in the mines, but also to elevate the national mining equipment and technology to the highest world standards.
\end{abstract}

\section{Introduction}

As the global rich mineral deposits are becoming depleted, the deposit development is performed with a deeper bedding and in much more difficult mining and geological conditions. This circumstance determines both the increase in the labor intensity and development costs, and the increased likelihood of emergencies. In recent years, the accidents have become more frequent at the Russian mining enterprises, aggravated not 
only by the significant damages, but, what is more tragic, also by the casualties. The objective and subjective causes of the tight situation are well-known, but the elimination efforts do not provide the desired effect.

A complete exclusion of the presence of people underground should be considered as a drastic remedy for preventing human casualties. It can be achieved only through the use of machinery and technology for manless mining using the automated control systems (ACS).

The high technology-related risks in the mining industry determine the relevance of safety improving during the underground mining. During the design and deployment of automation aids, it is important to consider the approaches that give a new meaning to the human purpose and machine functions [1].

\section{Results and discussion}

Global advances in the field development automation are rather modest, but the supervisory control evolution continues to go forward. For example, in Pilbars (Australia), the mines of the RioTinto consolidated group actively use the automated trucks and robotic drilling rigs [2]. The Thoresby Colliery British mine has a mobile tunneling machine for anchoring installation. At present, the mining robotics is being tested in mines in the USA, Canada, China and Africa. The technological transformation has also affected the CIS countries. In Russia, an automatic operational and supervisory control system was implemented at the Gazimursky plant (Trans-Baikal Territory) and will soon be introduced at the Uchalinsky ore mining and processing plant [3].

The significantly greater successful results have been achieved in the automation of certain types and groups of equipment [4, 5 - 12]. Since the end of the last century, the Ural State Mining University has been successfully developing geophysical methods and means for assessing the parameters of the rock mass stress pattern during the construction of underground facilities [5], as well as the control and prediction system for mine bumps and gas-dynamic phenomena during the underground mining of mineral deposits [6].

All tunneling machines and mining shovels, as well as the permanent installations, are equipped with the monitoring systems, in some cases the ACSs provide its adaptation to changes in the environmental conditions. The individual components of units are informationally and functionally interconnected. Actually, there are available or developed devices or systems using of which will make it possible to completely automate all permanent installations [4-16].

Thus, the favorable conditions have been laid for combining the in-mine equipment and permanent installations into a single complex under the control of operators located on the soil surface.

The Department of Engineering Mechanics of the Ural State Mining University has formed the concept of a "remote-controlled robotic complex for underground mining", according to which a surface-controlled system of mining equipment (ME) will absolve the miners from working underground.

The transformation of the ME into a robotic complex includes a number of stages:

- presentation of the unit or installation as a set of modules;

- equipment of each module with the information devices;

- integration of the module information devices into a system under the microprocessor control;

- integration of the module microprocessors into a single unit system under the onboard processor control;

- integration of the onboard processors of the units and installations into a single remote-controlled automated system (RCAS). 
The inclusion of an own microprocessor in the module is caused by the need for operational adaptation to changes in the environmental conditions and provides the module with individual technical intelligence, that is, its elevation to the level of an intelligent mechatronic module.

The combination of mechatronic modules with a control system leads to the formation of a mechatronic system [17].

Thus, the technological robotic complex is transformed into the mechatronic system of the underground ME. The mechatronic system is divided into separate subsystems, as shown in Fig. 1.

The formation of mechatronic subsystems is accompanied by the equipment rearrangement. For example, the electric drives of an underground ME and its controls, usually belonging to the group of electrically-powered equipment, become the module components. The mine hoisting installation joins the mining subsystem; therefore it also becomes a mechatronic subsystem.

One of the tasks that need to be solved during implementation of manless mining is the formation of tunneling machines and mining shovels in the form of a structure (group) of interconnected mechatronic and robotic modules. It will not only allow the subsystem to be provided with a given level of technical intelligence, but also reduce the cost of its assembly and installation [13 - 16].

The mining (or tunneling) group is a heterogeneous subsystem of robots, combined into a process chain. The link that determines the chain's performance is a robot influencing the mineral mass. Therefore, the centralized principle of a subsystem arrangement with a mining leading robot is advisable, and performance is the main criterion for the link interaction [18].

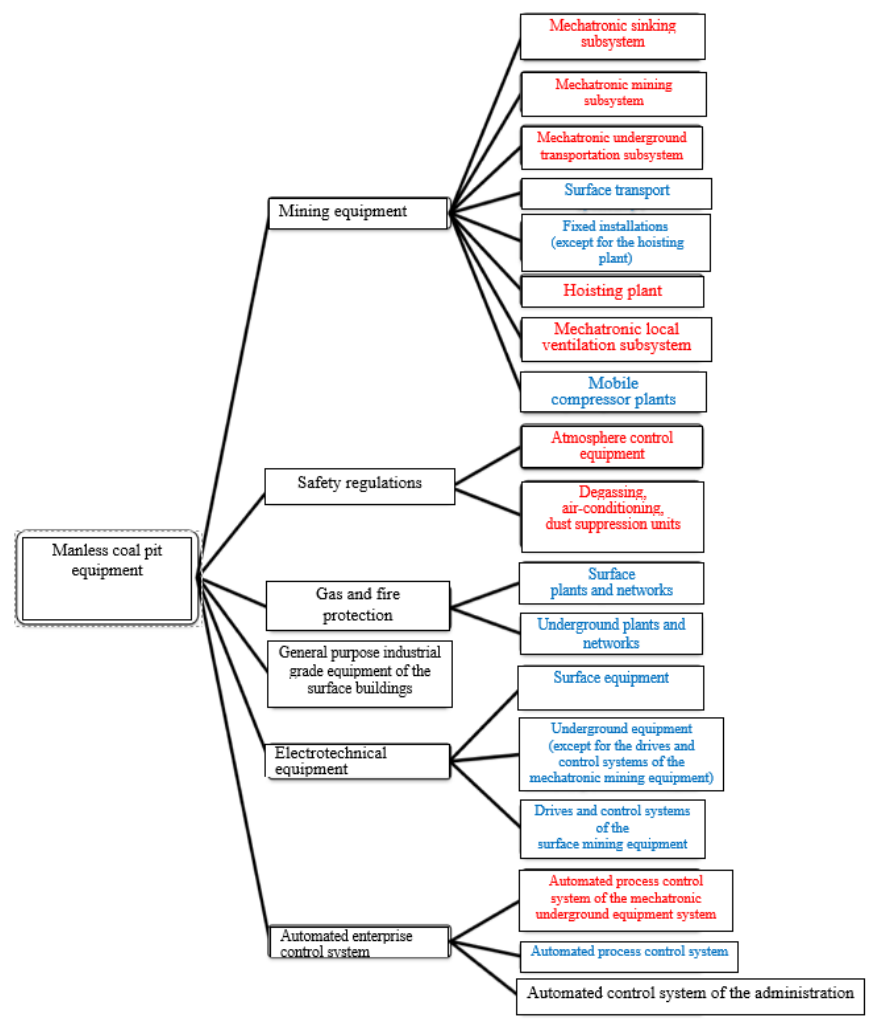

Fig.1. Equipment layout of a coal pit with manless mining. 
The effective functioning of the mechatronic system requires high survivability. The value of this requirement is higher, when the system operating conditions are more severe. In relation to the objects under consideration, one of the ways to ensure survivability is the scheduled replacement of modules with the expired failure-free operating period. The machine design provides for the independent replacement of the operator-controlled modules.

The performance of the machine is directly related to the type of its operating element. It seems advisable to use in the tunneling mechatronic subsystem the currently most advanced machine operating elements, such as Joy 12CM27 (USA) and Progress-2 (Karaganda State Technical University, Kazakhstan) [8].

The machine is equipped with a final support installation system. The Department of Engineering Mechanics of the Ural State Mining University is developing the support production from the polymer composites that will allow the machine to be equipped with a process system for composite preparation and molding of the support sections directly in the mine opening.

The local ventilation and safety modules can also be included in the mechatronic mining or tunneling subsystem. The feasibility of this measure should be established during the design stage.

The mine is controlled by an automated enterprise control system (AECS) that includes the following automated systems: the RCAS, he automated process control system (APCS) and the administration. The mechatronic subsystems that are directly related to the underground operations and require real-time control are controlled by the RCAS (shown in red in Fig. 1). The remaining equipment (shown in blue) is included in the scope of the APCS. The Administration automated control system is used for solving administrative issues.

The RCAS is based on the telemetry principles using the latest means of data acquisition, conversion and transmission. The system interface provides the most efficient and error-free performance of the operator throughout the entire shift.

The influence of the human factor reduces the performance of equipment with the ACS. At the beginning of the shift, the operator enters the operating mode, and towards the end of the shift, the fatigue begins to affect him, the reaction time is increased, and the probability of erroneous decisions is also increased. In view of the great socio-economic importance of the design object, close attention should be paid to the ergonomic aspect of the control system.

The operator's workplace is arranged from the perspective of the latest telemechanic achievements.

In recent years, new technical means have appeared that make it possible to increase the anthropometric and psychophysiological compatibility of the operator and ACS. First of all, the efforts should be aimed at improving the image acquisition, broadcast and perception.

The main channel for human perception of the environment is vision, it accounts for 80 - $90 \%$ of the total information flow entering the brain. Therefore, fatigue due to brain overload by the heterogeneous information flow is largely associated with the quantity and quality of video images.

The RCAS design provides four main directions for improving the alert system process for the operator:

- reduction in the number of control actions required for the high-quality $\mathrm{ME}$ functioning;

- relief of the visual channel due to other information channels;

- advance of the anthropometric specifications of the workplace;

- advance of the psychophysiological specifications of the workplace. 
The first area provides for the gradual expansion of the scope of decisions independently made by the RCAS and its approximation to the ACS, in other words, the natural system development towards full automation.

The second area is related to the expansion of the information component of audio messages. In this area, it is planned not only to use the conditional signals, but also voice communication between the operator and the RCAS.

The anthropometric specifications of the workplace mean the adaptability of the RCAS interfaces to human physiology.

In particular, when operating the tunneling machine or mining shovel, the operator shall see the recovery area, have an idea of the operating tool condition, control the quality of the final support constructed by the machine, etc. Therefore, the mechatronic subsystem is equipped with the relevant "vision organs": color rotary video cameras with the targeting devices, focusing drives, light assemblies and screen wipers. The video cameras should either provide a panoramic image in front of the operator, or rotate, duplicating the movements of the operator's head.

The psychophysiological specifications of the workplace include the image quality mentioned above. This is not so much about the image brightness and contrast that is quite reliably provided by the level of lighting and computer image processing, but about receipt of a stereo image, or 3D image. There are various ways to create stereo images that, however, are not free from defects. One of the tasks of the RCAS design should be the implementation of an optimal method for obtaining 3D-images on the control panel screen according to the quality-cost criteria.

\section{Conclusion}

Safety provision for the miners and efficiency increase of driving and mining equipment are urgent state problems. For its solution, it is necessary to combine the equipment groups for underground operations into the mechatronic system consisting of subsystems by the type of equipment, controlled from the surface and performing the manless mining.

The conversion of driving and mining complexes into the mechatronic subsystems requires a new approach to its design. The complexes are composed of the intelligent mechatronic modules that coherently execute the operator's commands.

The control system for underground equipment is based on the telemetry principles using the latest means of data acquisition, conversion and transmission. The control system interface provides the most efficient and error-free performance of the operator throughout the entire shift.

\section{References}

1. IOP Conference Series: Earth and Environmental Science, (2018)

2. Geographies of the labour process: automation and the spatiality of mining, (2016)

3. V.A. Spenst, Notes of the Mining Institute, 235, (2019)

4. V.M. Tauger, Mining Journal, 6, 63 (2012)

5. V.B. Pisetskiy, E.S. Lapin, I.V. Abaturova, A.E Zudilin, Mining Journal, 9, 49 (2014)

6. E.S. Lapin, V.B. Pisetskiy, A.G. Babenko, Yu.V. Patrushev, Labor safety in industry, 4, 18 (2014)

7. V.P. Baskakov, M.N. Yakimov, Mining Journal, 6, 28, (2013)

8. The Beginnings of Crowd sourced Analytics, (2015)

9. C. Jamasmie, China's Zijin hands US\$298 million to partner Barrick Gold, (2015)

10. D. Milstead, The Globe and Mail (2015) 
11. World Nuclear Association (2015)

12. The Northern Miner (2015)

13. G. Parkinson, Renew Economy (2015)

14. M.S. Kostina, V.O. Maslenko, E.I. Kazakova, Automated control of extracting machines in the deposit profile

15. M.A. Lemeshko, R.Yu. Volkov, Actual issues of the humanities and natural sciences, 9, 49 (2014)

16. Automated process control system for a mine winding plant

17. Yu.V. Poduraev, Fundamentals of mechatronics, 102, (2000)

18. D.A. Beloglazov, A.R. Gaiduk, E.Yu. Kosenko, et. al., Group control of moving objects in the unfixed environments, 305 (2015) 